\title{
A Functional Scoring System to Assess the Level of Impairment in Patients with Low Vision Impairment
}

\author{
Geeta Shroff \\ Nutech Mediworld, New Delhi, India \\ Email: geetashroff@hotmail.com
}

How to cite this paper: Shroff, G. (2017) A Functional Scoring System to Assess the Level of Impairment in Patients with Low Vision Impairment. Open Journal of Ophthalmology, 7, 204-215.

https://doi.org/10.4236/ojoph.2017.73028

Received: July 11, 2017

Accepted: August 15, 2017

Published: August 18, 2017

Copyright $\odot 2017$ by author and Scientific Research Publishing Inc. This work is licensed under the Creative Commons Attribution-NonCommercial International License (CC BY-NC 4.0).

http://creativecommons.org/licenses/by-nc/4.0/ (c) (i) (8) Open Access

\begin{abstract}
Background: Low vision is referred to as visual impairment (VI) if it is not cured through surgery, drugs, spectacles or contact lenses. It interferes with day-to-day living activities and is associated with the major eye blinding diseases. Numerous tests are used to carry out diagnosis of VI, but their outcomes are unreliable. Objective: To develop a functional scoring system, for accessing the ailment of patients with VI based on observations and clinical symptoms. Methods and Findings: We prepared the list of all possible symptoms that were associated with low vision. Based on this list, we established a scoring system, Nutech Functional Score (NFS), which is a 33-point positional and directional scoring system that evaluates the patient with VI. The scores have been converted into numeric values for conducting probability based studies. All the symptoms are graded between 1 to 5 that runs in $\mathrm{BAD} \rightarrow \mathrm{GOOD}$ direction. Conclusion: NFS is a distinctive tool that can be used globally to evaluate the patients with low vision.
\end{abstract}

\section{Keywords}

Nutech Functional Score (NFS), Visual Impairment, Cortical Visual Impairment (CVI), Positional Scoring System, Ocular Visual Impairment (OVI)

\section{Introduction}

Visual impairment (VI) is an acute reduction in the visual acuity that cannot be rectified with medication, surgical operation, spectacles or contact lenses [1] [2]. VI is usually associated with major eye blinding diseases such as cataracts, diabetic retinopathy, glaucoma, and age-related macular degeneration (AMD) that crop up steadily deprived of warning signs [2]. Among these diseases, cataract is the primary cause of VI worldwide followed by glaucoma, AMD, diabetic reti- 
nopathy and trachoma [3]. According to the World Health Organization (WHO), globally there are 135 million people with low vision, 45 million are blind and this number is expected to reach up to 76 million by 2020 [4]. In India, it is estimated that the prevalence of blindness is about $1.1 \%$ in the major states and $1.38 \%$ in the north-eastern states [5].

An individual experiences blindness and VI due to different causes as cataracts, glaucoma, macular degeneration and retinitis pigmentosa [6]. Numerous others have uncorrected refractive errors that might be improved without difficulty with glasses or contact lenses [7] [8] [9]. It is estimated that up to $5 \%$ of people with VI are totally blind [6]. VI is an incurable disease [10] but screening for disorders might help an individual in improving the quality of life or slow down progression of vision loss [11].

There are two categories of VI in younger children: ocular visual impairment (OVI) and cortical visual impairment (CVI) [11]. In OVI, the eye building tissues are underdeveloped or get damaged due to an insult or infection that causes unclear or incomplete vision. While in CVI, the organization of tissues is healthy but the brain gets impaired due to damage to the visual centers of the brain [12]. However, ocular disorders are among the prominent cause of VI in young children [11] [13].

There are various estimation practices and measures used to evaluate patients with VI. Visual acuity is the best variable that categorizes vision loss and is an established measure for describing VI by the WHO [14]. Snellen chart is the most common tool for assessing visual acuity [4]. Though readily available, easy to perform and universally accepted, Snellen chart has some disadvantages. The most significant difficulty faced with the design of the Snellen chart is uneven progression, variable letter size, no equal legibility and possesses greater crowding phenomenon [7] [15] [16]. Moreover, the diagnostic accurateness of Snellen chart is problematic because a clinically appropriate reference standard is not established [17]. Further, we cannot statistically assess parametric analysis with this decimal progression sequence, even if converted to another form. It fails to evaluate visual acuity statistically at the right distance and under suggested points of illumination [16].

There are scoring systems for numerous other medical disorders such as cerebral palsy [8], spinal cord injury [18] and multiple sclerosis [19]. Nonetheless, there is no such separate system to evaluate the patients with VI. We developed a numeric method, Nutech Functional Score (NFS), to measure the ailment of patients with VI based on observations and clinical symptoms. NFS for vision disorder is a 33-point positional and directional scoring system that can be used to assess or validate the diagnosis of low vision or VI.

\section{Methodology}

We have been treating patients with various eye diseases such as glaucoma, CVI, AMD, since 2000. Cases associated with ocular diseases admitted at our facility visited directly or were referred by other hospitals/institutions. These patients 
were previously diagnosed. We assess the event equally for common and rare symptoms, and record them in the diagnostic history. These patients provided written informed consent. An independent Institutional Ethics Committee (IEC) of Nutech Mediworld approved the current study. The study was conducted in compliance with the "Declaration of Helsinki" and good clinical practices (GCP).

Thus, over the years, a list of symptoms was prepared which contained all the possible symptoms and was used to diagnose patients with vision disorders. This list of symptoms is revised from time to time to maintain accuracy. Each symptom is evaluated on basis of five ordinal grades running in BAD $\rightarrow$ GOOD direction. The grades have been converted into numeric values for conducting probability based analysis. We used NFS scoring system for vision disorders to assess patients with low vision or VI who were previously assessed by the ophthalmology department or specialized clinics.

\section{Results}

The institute developed a 33-point positional (each symptom is sub-graded with a distinct score) and directional (bad to good) scoring system that authenticates the patients with VI. It measures the disorders through symptoms, namely, NFS grades which are grouped to determine the symptoms. These symptoms include anterior chamber depth (deep), anterior chamber depth (shallow), blurring of vision, burning sensation of eye, color blindness, double vision, fatigue (eye), floaters (colored halo), foreign body sensation etc. NFS scores for all the symptoms are presented in Appendix 1. If a patient is not associated with the symptom, then it is graded as not affected in affliction (NAA). These five ordinal scores $(1,2,3,4,5)$ run in the direction of $1 \rightarrow 5$ i.e. BAD $\rightarrow$ GOOD. These five grades from $1 \rightarrow 5$ signify worst, bad, not so bad, good and normal, correspondingly. These five grades that lie in a range of $(0.5,5.5)$ are equidistant to each other and are continuous. The scores have been converted into numeric values to facilitate the conduct of probability based studies which require a range of $(-1,1)$ or $(0,1)$. This configuration can be used collectively for one symptom. The polynomial smoothing and graphical methods have been used to derive an equation for converting categorical scores into numeric scores. The equation is as follows:

$$
Y_{n}=0.096 \times\left(Y_{c}+0.5\right)-0.166
$$

where, $Y_{n}=$ numeric score and $Y_{c}=$ categorical score.

Table 1 shows how five/three categorical grades $(0.5$ - 5.5) for symptoms can be converted to five/three numeric grades in the range $(0,1)$.

\section{Discussion}

Nutech Mediworld established NFS for vision to evaluate the ailment of patients with VI on the basis of observations and clinical indications. NFS designates its usefulness by detecting even the minor improvement in terms of grades associ- 
Table 1. Conversion table from categorical grades to numeric range for NFS.

\begin{tabular}{ccccccc}
\hline \multirow{2}{*}{ No. of grades } & Numeric & \multicolumn{5}{c}{ Categorical grades } \\
\cline { 3 - 7 } & & $\mathbf{1}$ & $\mathbf{2}$ & $\mathbf{3}$ & $\mathbf{4}$ & $\mathbf{5}$ \\
\hline \multirow{2}{*}{5} & Score & 0.12 & 0.31 & 0.50 & 0.69 & 0.89 \\
& Range & $0-0.24$ & $0.24-0.38$ & $0.38-0.62$ & $0.62-0.76$ & $0.76-1.00$ \\
& Score & 0.17 & 0.50 & 0.83 & - & - \\
& Range & $0-0.33$ & $0.33-0.67$ & $0.67-1.00$ & - & - \\
\hline
\end{tabular}

ated with symptoms and after clinical investigation. Various other scoring systems are also used for evaluating VI like rasch analysis. Like rasch analysis, NFS also places the items and the patients along a single ratio scale, the units being logits. For ease of interpretation and consistent with the idea, the higher scores represent better functioning.

Huo and colleagues in their study established a six level measure of functional vision. These six levels used were on the basis of symptoms such as light perception only, occasional fixation on large objects, faces or movement, occasional fixation on small objects (i.e., pennies or stickers) or reliable fixation on faces etc. They used this system as a method of enumerating functional vision and calculated the grades in terms of variations in the levels. But this system fails to explain how the patient really used vision in activities of average life and do not provide any information about the reliability or validity of the scale [20].

Dutton in 2004 established an assessment tool for the children suffering from cortical visual impairment (CVI). The goal of this tool was to determine the vision accessible for communication, education, and movement in the environment. The recommended observations were on the basis of characteristic vision skills (acuity, contrast sensitivity, visual fields) and visual processing skills (simultaneous visual processing problems, recognition, problems with reading, problems with orientation, visual memory etc.). However, this assessment tool does not provide any directions for precise observations or direct valuation of these skills. Besides this, the assessment system is also not able to provide information for the use of findings from observations for educational interventions [9].

NFS scoring system appears to be a simple and suitable method to confirm the diagnosis of patients with low vision based upon symptoms. This assessment system runs in 1 - 5 direction, i.e., $\mathrm{BAD} \rightarrow \mathrm{GOOD}$ which signifies worst, bad, not so bad, good and normal, respectively. This system has procured nearly all the possible symptoms that are connected with VI. NFS is a numeric system that has been authenticated statistically and can benefit in evaluating patients with low vision due to refractive errors or either due to diseases.

Let's take an example to describe how NFS is used to grade a patient with low vision. We assume a female patient aged 21 years with low vision is graded with NFS.

Similarly, we have graded all the other symptoms included in NFS for this patient (Table 2). The total NFS score is calculated by counting the grades of the 
Table 2. A hypothetical example showing NFS grades of a patient before and after therapy.

\begin{tabular}{|c|c|c|c|c|}
\hline \multirow{2}{*}{$\begin{array}{c}\text { Symptoms } \\
\text { Eye }\end{array}$} & \multicolumn{2}{|c|}{ NFS grades before therapy } & \multicolumn{2}{|c|}{ NFS grades after therapy } \\
\hline & $\mathrm{RT}$ & $\mathrm{LT}$ & $\mathrm{RT}$ & $\mathrm{LT}$ \\
\hline Blurring of vision & 1 & 1 & 4 & 4 \\
\hline Pain & 2 & 2 & 5 & 4 \\
\hline Fatigue & NA & NA & NA & NA \\
\hline Itching & NA & NA & NA & NA \\
\hline Burning sensation & 2 & 2 & 5 & 5 \\
\hline Redness & 1 & 1 & 4 & 4 \\
\hline Foreign body sensation & NA & $\mathrm{NA}$ & NA & NA \\
\hline Sensitivity to light (photopsia) & NA & NA & NA & NA \\
\hline Night blindness & NA & NA & NA & NA \\
\hline Color blindness & NA & NA & NA & NA \\
\hline Floaters (colored halo) & NA & NA & NA & NA \\
\hline Watering (Lacrimation) & NA & $\mathrm{NA}$ & NA & NA \\
\hline Double vision & NA & NA & NA & NA \\
\hline Visual acuity-distance vision & 2 & 2 & 4 & 3 \\
\hline Visual acuity (near vision) & 3 & 3 & & \\
\hline Pupil-size-dilated & NA & NA & NA & NA \\
\hline Pupil-size (constricted) & NA & NA & NA & NA \\
\hline Anterior chamber depth-shallow & NA & NA & NA & NA \\
\hline Anterior chamber depth-deep & 0 & 0 & 2 & 2 \\
\hline Squint & 2 & 2 & 4 & 4 \\
\hline Nystagmus & 0 & 0 & 2 & 0 \\
\hline Fundoscopy-media & NA & NA & NA & NA \\
\hline Fundoscopy-lens & 0 & 0 & 3 & 3 \\
\hline Fundoscopy-Optic disc color & NA & $\mathrm{NA}$ & NA & NA \\
\hline Fundoscopy-cup size & 0 & 0 & 1 & 1 \\
\hline Fundoscopy-macula-edema & NA & $\mathrm{NA}$ & NA & NA \\
\hline Fundoscopy-retinal vessels & NA & NA & NA & NA \\
\hline Fundoscopy-retinal exudates & NA & NA & NA & NA \\
\hline Fundoscopy-retinal pigmentation & NA & $\mathrm{NA}$ & NA & NA \\
\hline Fundoscopy-retinal detachments & NA & NA & NA & NA \\
\hline Field of vision-OAP & 2 & 2 & 3 & 0 \\
\hline Tonometry-IOP-high & NA & NA & NA & NA \\
\hline Tonometry-IOP-low & 2 & 2 & 4 & 4 \\
\hline Total & 17 & 17 & 41 & 34 \\
\hline
\end{tabular}


all symptoms. In this case, the patient scored 17 for both the eyes. Let's suppose that this patient undergoes therapy for low vision. After the therapy, we found that the total NFS score for symptoms increased as the patient moved from grades $1 \rightarrow 5$ in $\mathrm{BAD} \rightarrow \mathrm{GOOD}$ direction showing improvement. The grades after the therapy were calculated as 41 for the right and 34 for the left eye. The NFS scoring system is numeric which means grades can be added by means of improvement either in "number of symptoms" or "all" and it can be subtracted if the patient symptoms "further deteriorated" or that "disease affects some other part of the body". The other advantage is that the evaluation system is suitable for the patients of all ages with diminished complexities that would rise during evaluation process. Therefore, the information obtained with NFS is reliable, much more precise and reveals sustainable improvement in patients suffering from low vision.

\section{Conclusion}

Summarizing, there is a lack of discrete scoring system for patients with VI. The eye test and other ocular tests have low specificity and sensitivity. A numeric scoring system like NFS can be a useful tool that may help doctors globally to authenticate the diagnosis of low vision in patient.

\section{Acknowledgements}

The author acknowledges all the doctors, staff and patients of the Nutech Mediworld. The author also acknowledges Knowledge Isotopes Pvt. Ltd. (http://www.knowledgeisotopes.com) for the medical writing support.

\section{Funding Sources}

No funding sources were used to sponsor this study.

\section{Disclosures and Ethics}

The authors declare no conflict of interest associated with the publication of this manuscript.

\section{References}

[1] Dandona, L. and Dandona, R. (2006) Revision of Visual Impairment Definitions in the International Statistical Classification of Diseases. BMC Medicine, 4, 7. https://doi.org/10.1186/1741-7015-4-7

[2] (2015) Blindness and Vision Impairment. Centre for Disease Control and Prevention.

[3] Resnikoff, S., Pascolini, D., Etya'ale, D., Kocur, I., Pararajasegaram, R., Pokharel, G.P. and Mariotti, S.P. (2004) Global Data on Visual Impairment in the Year 2002. Bull World Health Organ, 82, 844-851.

[4] Lívia, C. and Luiz, J.R.R. (2009) Association between Visual Deficit and Clinical-Functional Characteristics among Community-Dwelling Older Adults. The Brazilian Journal of Physical Therapy, 5.

[5] Joshi, M. (2015) Epidemiological Study of Patients Availing Free Cataract Services 
of National Programme of Control of Blindness. Journal of Clinical Opthalmology \& Research, 3, 9-13. https://doi.org/10.4103/2320-3897.149341

[6] (2014) Chapter 7: Restoring Vision to the Blind: Advancements in Vision Aids for the Visually Impaired. Translational Vision Science \& Technology, 3, 9.

https://doi.org/10.1167/tvst.3.7.9

[7] Hussain, B., Saleh, G.M., Sivaprasad, S. and Hammond, C.J. (2006) Changing from Snellen to LogMAR: Debate or Delay? Clinical \& Experimental Ophthalmology, 34, 6-8. https://doi.org/10.1111/j.1442-9071.2006.01135.x

[8] Palisano, R., Rosenbaum, P., Walter, S., Russell, D., Wood, E. and Galuppi, B. (1997) Development and Reliability of a System to Classify Gross Motor Function in Children with Cerebral Palsy. Development Medicine \& Child Neurology, 39, 214-223. https://doi.org/10.1111/j.1469-8749.1997.tb07414.x

[9] Dutton, G.N. (2006) Cerebral Visual Impairment Working within and around the Limitations of Vision. Proceedings of the Summit on Cerebrall Cortical Visual Impairment. Educational, Family, and Medical Perspectives, April 30 2005, 3.

[10] (2002) Visual Impairment and Blindness. Independent Study Course Released: April 2002. Department of Veterans Affairs Employee Education System.

[11] Newcomb, S. (2009) Reliability of the CVI Range-A Functional Vision Assessment for Children with Cortical Visual Impairment. Journal of Visual Impairment and Blindness, 104, 637-647.

[12] Malkowicz, D.E., Myers, G. and Leisman, G. (2006) Rehabilitation of Cortical Visual Impairment in Children. International Journal of Neuroscience, 116, 1015-1033. https://doi.org/10.1080/00207450600553505

[13] Alimovic, S. and Mejaski-Bosnjak, V. (2011) Stimulation of Functional Vision in Children with Perinatal Brain Damage. Collegium Antropologicum, 35, 3-9.

[14] World Health Organization (WHO) (2004) Vision 2020 the Right to Site. Developing an Action Plan to Prevent Blindness and National, Provincial and District Levels. Geneva.

[15] McGraw, P., Winn, B. and Whitaker, D. (1995) Reliability of the Snellen Chart. $B M$ J, 310, 1481-1482. https://doi.org/10.1136/bmj.310.6993.1481

[16] Kalpana, S.K.J. and Jayarajini, S. (2013) Comparison of Static Visual Acuity between Snellen and Early Treatment Diabetic Retinopathy Study Charts. International Journal of Educational Research and Development, 2, 82-88.

[17] Chou, R., Dana, T. and Bougatsos, C. (2009) Screening for Visual Impairment in Older Adults: Systematic Review to Update the 1996 US Preventive Services Task Force Recommendation. U.S. Preventive Services Task Force Evidence Syntheses, Formerly Systematic Evidence Reviews. Rockville.

[18] Kirshblum, S.C., Burns, S.P., Biering-Sorensen, F., Donovan, W., Graves, D.E., Jha, A., Johansen, M., Jones, L., Krassioukov, A., Mulcahey, M.J., Schmidt-Read, M. and Waring, W. (2011) International Standards for Neurological Classification of Spinal Cord Injury (Revised 2011). The Journal of Spinal Cord Medicine, 34, 535-546. https://doi.org/10.1179/204577211X13207446293695

[19] Orla, G. and Butzkueven, H. (2008) Measurement of Disability in Multiple Sclerosis. Neurology Asia, 13, 153-156.

[20] Huo, R., Burden, S.K., Hoyt, C.S. and Good, W.V. (1999) Chronic Cortical Visual Impairment in Children: Aetiology, Prognosis, and Associated Neurological Deficits. British Journal of Ophthalmology, 83, 670-675.

https://doi.org/10.1136/bjo.83.6.670 


\section{Supplementary Data}

Appendix 1. Nutech Functional Score for Vision Impairment.

\begin{tabular}{|c|c|c|c|}
\hline S. No. & Parameters & Description & Score \\
\hline \multirow{6}{*}{1} & \multirow{6}{*}{ Blurring of vision } & Not afflicted in vision & NAA \\
\hline & & Very severe: no outline of image seen & 1 \\
\hline & & Severe: outline seen but no shape & 2 \\
\hline & & $\begin{array}{l}\text { Moderate: both outline and shape seen but } \\
\text { blurred }\end{array}$ & 3 \\
\hline & & Mild: very slight blurring & 4 \\
\hline & & Becomes normal & 5 \\
\hline \multirow{6}{*}{2} & \multirow{6}{*}{ Pain-eye } & Not afflicted in vision & NAA \\
\hline & & Very severe: IV analgesics required & 1 \\
\hline & & Severe: IM analgesics required & 2 \\
\hline & & Moderate: oral analgesics required & 3 \\
\hline & & Mild: tolerable, no medication required & 4 \\
\hline & & Becomes normal & 5 \\
\hline \multirow{6}{*}{3} & \multirow{6}{*}{ Fatigue-eye Asthenopia } & Not afflicted in vision & NAA \\
\hline & & Very severe: all the time eyes closed & 1 \\
\hline & & Severe: can open eyes but do not follow direction & 2 \\
\hline & & Moderate: can open eyes and follow direction & 3 \\
\hline & & $\begin{array}{l}\text { Mild: open eyes continuously but difficulty } \\
\text { occasionally }\end{array}$ & 4 \\
\hline & & Becomes normal & 5 \\
\hline \multirow{6}{*}{4} & \multirow{6}{*}{ Itching of eye } & Not afflicted in vision & NAA \\
\hline & & Very severe: constant & 1 \\
\hline & & Severe: for a period of $2-4$ hours & 2 \\
\hline & & Moderate: for a period of $8-12$ hours & 3 \\
\hline & & Mild: 1 to 2 occasions of itching & 4 \\
\hline & & Becomes normal & 5 \\
\hline \multirow{6}{*}{5} & \multirow{6}{*}{$\begin{array}{l}\text { Burning sensation of } \\
\text { eye }\end{array}$} & Not afflicted in vision & NAA \\
\hline & & Very severe: constant & 1 \\
\hline & & Severe: for a period of $2-4$ hours & 2 \\
\hline & & Moderate: for a period of $8-12$ hours & 3 \\
\hline & & Mild: 1 to 2 occasions of burning & 4 \\
\hline & & Becomes normal & 5 \\
\hline \multirow{6}{*}{6} & \multirow{6}{*}{ Redness of eye } & Not afflicted in vision & NAA \\
\hline & & Very severe: full sclera involved and constant & 1 \\
\hline & & Severe: peripheral sclera clear & 2 \\
\hline & & Moderate: around pupil redness & 3 \\
\hline & & Mild: redness occurs for some time in the day & 4 \\
\hline & & Becomes normal & 5 \\
\hline
\end{tabular}




\section{Continued}

\begin{tabular}{|c|c|c|c|}
\hline \multirow{6}{*}{7} & \multirow{6}{*}{ Foreign body sensation } & Not afflicted in vision & NAA \\
\hline & & Very severe: pin prick like with pain and constant & 1 \\
\hline & & Severe: pin prick like without pain and constant & 2 \\
\hline & & Moderate: constant and discomfort & 3 \\
\hline & & Mild: occasional sensation & 4 \\
\hline & & Becomes normal & 5 \\
\hline \multirow{6}{*}{8} & \multirow{6}{*}{$\begin{array}{c}\text { Sensitivity to light } \\
\text { Photopsia }\end{array}$} & Not afflicted in vision & NAA \\
\hline & & Hypersensitivity to any light/stays in dark & 1 \\
\hline & & Hypersensitivity to room light & 2 \\
\hline & & Hypersensitivity to sun light & 3 \\
\hline & & Hypersensitivity to bright flashy lights & 4 \\
\hline & & Hypersensitivity to light disappeared & 5 \\
\hline \multirow{6}{*}{9} & \multirow{6}{*}{ Night blindness } & Not afflicted in vision & NAA \\
\hline & & Very severe: No perception & 1 \\
\hline & & $\begin{array}{l}\text { Severe: adaption present but taken very long } \\
\text { time }>1 \frac{1 / 2}{\text { hours }}\end{array}$ & 2 \\
\hline & & $\begin{array}{l}\text { Moderate: adaption present but taken very long } \\
\text { time } 15 \text { - } 30 \text { minutes }\end{array}$ & 3 \\
\hline & & $\begin{array}{l}\text { Mild: adaption present but taken very long time } 5 \\
-10 \text { minutes }\end{array}$ & 4 \\
\hline & & Becomes normal & 5 \\
\hline \multirow{6}{*}{10} & \multirow{6}{*}{ Color blindness } & Not afflicted in vision & NAA \\
\hline & & Complete loss & 1 \\
\hline & & Monochromatic & 2 \\
\hline & & Dichromatic & 3 \\
\hline & & Trichromatic & 4 \\
\hline & & Becomes normal & 5 \\
\hline \multirow{6}{*}{11} & \multirow{6}{*}{ Floaters colored halos } & Not afflicted in vision & NAA \\
\hline & & $>6$ & 1 \\
\hline & & Between 5 to 6 & 2 \\
\hline & & Between 3 to 4 & 3 \\
\hline & & Between 1 to 2 & 4 \\
\hline & & Floaters disappeared & 5 \\
\hline \multirow{6}{*}{12} & \multirow{6}{*}{ Lacrimation epiphora } & Not afflicted in vision & NAA \\
\hline & & Very severe: Hemorrhagic & 1 \\
\hline & & Severe: purulent & 2 \\
\hline & & Moderate: mucoid & 3 \\
\hline & & Mild: watery & 4 \\
\hline & & Becomes normal & 5 \\
\hline
\end{tabular}




\section{Continued}

\begin{tabular}{|c|c|c|c|}
\hline \multirow{6}{*}{13} & \multirow{6}{*}{ Double vision } & Not afflicted in vision & NAA \\
\hline & & Present and constant & 1 \\
\hline & & Present but occurs 8 - 10 times per day & 2 \\
\hline & & Present but occurs 4 - 8 times per day & 3 \\
\hline & & Present but occurs $1-2$ times per day & 4 \\
\hline & & Becomes normal & 5 \\
\hline \multicolumn{4}{|c|}{ Clinical Signs } \\
\hline \multirow{6}{*}{14} & \multirow{6}{*}{$\begin{array}{l}\text { Visual acuity } \\
\text { distance vision }\end{array}$} & Not afflicted in vision & NAA \\
\hline & & Complete loss & 1 \\
\hline & & $\mathrm{P} / \mathrm{R}, \mathrm{P} / \mathrm{L}$ present & 2 \\
\hline & & $\mathrm{CF} 3^{\prime}, 2^{\prime}, 1^{\prime}$ and $\mathrm{HM}$ & 3 \\
\hline & & Between $1 / 60$ to $6 / 9$ & 4 \\
\hline & & Becomes normal: 6/6 & 5 \\
\hline \multirow{6}{*}{15} & \multirow{6}{*}{$\begin{array}{l}\text { Visual acuity near } \\
\text { vision }\end{array}$} & Not afflicted in vision & NAA \\
\hline & & Complete loss & 1 \\
\hline & & Vision 2 - 5 centimeters & 2 \\
\hline & & Vision 5 - 10 centimeters & 3 \\
\hline & & Vision 10 - 20 centimeters & 4 \\
\hline & & Becomes normal & 5 \\
\hline \multirow{6}{*}{16} & \multirow{6}{*}{ Pupil-size dilated } & Not afflicted in vision & NAA \\
\hline & & Fully dilated & 1 \\
\hline & & Between 6 - $9 \mathrm{~mm}$ & 2 \\
\hline & & Between $3-6 \mathrm{~mm}$ & 3 \\
\hline & & Between 1 - $3 \mathrm{~mm}$ & 4 \\
\hline & & Becomes normal & 5 \\
\hline \multirow{6}{*}{17} & \multirow{6}{*}{ Pupil-size constricted } & Not afflicted in vision & NAA \\
\hline & & Occluded pupil & 1 \\
\hline & & Between 5 - $6 \mathrm{~mm}$ & 2 \\
\hline & & Between 2 - $4 \mathrm{~mm}$ & 3 \\
\hline & & Between 1 - $2 \mathrm{~mm}$ & 4 \\
\hline & & Becomes normal & 5 \\
\hline \multirow{4}{*}{18} & \multirow{4}{*}{$\begin{array}{c}\text { Slit lamp } \\
\text { examinations } \\
\text { anterior chamber } \\
\text { depth Shallow }\end{array}$} & Not afflicted in vision & NAA \\
\hline & & Flat $\mathrm{AC}$ to $<1 \mathrm{~mm}$ & 1 \\
\hline & & Between $1-2 \mathrm{~mm}$ & 3 \\
\hline & & Becomes normal 2 - $3 \mathrm{~mm}$ & 5 \\
\hline \multirow{3}{*}{19} & \multirow{3}{*}{$\begin{array}{c}\text { Slit lamp } \\
\text { examinations } \\
\text { anterior chamber } \\
\text { depth deep }\end{array}$} & Not afflicted in vision & NAA \\
\hline & & Deeper $>3 \mathrm{~mm}$ & 1 \\
\hline & & Becomes normal $2-3 \mathrm{~mm}$ & 5 \\
\hline
\end{tabular}




\section{Continued}

\begin{tabular}{|c|c|c|c|}
\hline \multirow{6}{*}{20} & \multirow{6}{*}{ Squint } & Not afflicted in vision & NAA \\
\hline & & Squint with nystagmus with visual defects & 1 \\
\hline & & Squint with visual defect & 2 \\
\hline & & Squint with nystagmus & 3 \\
\hline & & Squint & 4 \\
\hline & & Becomes normal & 5 \\
\hline \multirow{6}{*}{21} & \multirow{6}{*}{ Nystagmus } & Not afflicted in vision & NAA \\
\hline & & Nystagmus with squint with visual defect & 1 \\
\hline & & Nystagmus with visual defect & 2 \\
\hline & & Nystagmus with squint & 3 \\
\hline & & Nystagmus & 4 \\
\hline & & Nystagmus disappeared & 5 \\
\hline \multirow{6}{*}{22} & \multirow{6}{*}{$\begin{array}{c}\text { Fundoscopy } \\
\text { media/hazyness }\end{array}$} & Not afflicted in vision & NAA \\
\hline & & Very severe & 1 \\
\hline & & Severe & 2 \\
\hline & & Moderate & 3 \\
\hline & & Mild & 4 \\
\hline & & Becomes normal & 5 \\
\hline \multirow{3}{*}{23} & \multirow{3}{*}{ Fundoscopy lens } & Not afflicted in vision & NAA \\
\hline & & Cataractous changes & 1 \\
\hline & & Becomes normal & 5 \\
\hline \multirow{3}{*}{24} & \multirow{3}{*}{$\begin{array}{l}\text { Fundoscopy optic } \\
\text { disc colour }\end{array}$} & Not afflicted in vision & NAA \\
\hline & & Pale & 1 \\
\hline & & Becomes normal & 5 \\
\hline \multirow{3}{*}{25} & \multirow{3}{*}{ Fundoscopy cup size } & Not afflicted in vision & NAA \\
\hline & & Abnormal & 1 \\
\hline & & Becomes normal & 5 \\
\hline \multirow{3}{*}{26} & \multirow{3}{*}{$\begin{array}{c}\text { Fudoscopy } \\
\text { macula-edema }\end{array}$} & Not afflicted in vision & NAA \\
\hline & & Present & 1 \\
\hline & & Edema subsides & 5 \\
\hline \multirow{3}{*}{27} & \multirow{3}{*}{$\begin{array}{l}\text { Fundoscopy retinal } \\
\text { vessels }\end{array}$} & Not afflicted in vision & NAA \\
\hline & & Abnormality present & 1 \\
\hline & & Becomes normal & 5 \\
\hline \multirow{3}{*}{28} & \multirow{3}{*}{$\begin{array}{c}\text { Fundoscopy retinal } \\
\text { exudates }\end{array}$} & Not afflicted in vision & NAA \\
\hline & & Present & 1 \\
\hline & & Absent & 5 \\
\hline \multirow{3}{*}{29} & \multirow{3}{*}{$\begin{array}{l}\text { Fundoscopy } \\
\text { retinal pigmentation }\end{array}$} & Not afflicted in vision & NAA \\
\hline & & Present & 1 \\
\hline & & Absent: becomes normal & 5 \\
\hline
\end{tabular}




\section{Continued}

\begin{tabular}{|c|c|c|c|}
\hline \multirow{3}{*}{30} & \multirow{3}{*}{$\begin{array}{l}\text { Fundoscopy } \\
\text { retinal detachments }\end{array}$} & Not afflicted in vision & NAA \\
\hline & & Present & 1 \\
\hline & & Absent: becomes normal & 5 \\
\hline \multicolumn{4}{|c|}{ Investigations } \\
\hline \multirow{6}{*}{31} & \multirow{6}{*}{$\begin{array}{l}\text { Field of vision by } \\
\text { OAP }\end{array}$} & Not afflicted in vision & NAA \\
\hline & & Complete loss of field of vision & 1 \\
\hline & & Eccentric loss of field of vision & 2 \\
\hline & & Central loss of field of vision & 3 \\
\hline & & Peripheral loss of field of vision & 4 \\
\hline & & Becomes normal & 5 \\
\hline \multirow{6}{*}{32} & \multirow{6}{*}{ Tonometry IOP high } & Not afflicted in vision & NAA \\
\hline & & $>35 \mathrm{~mm} \mathrm{Hg}$ & 1 \\
\hline & & $>30 \mathrm{~mm} \mathrm{Hg}$ to $35 \mathrm{~mm} \mathrm{Hg}$ & 2 \\
\hline & & $>25 \mathrm{~mm} \mathrm{Hg}$ to $30 \mathrm{~mm} \mathrm{Hg}$ & 3 \\
\hline & & $>21 \mathrm{~mm} \mathrm{Hg}$ to $25 \mathrm{~mm} \mathrm{Hg}$ & 4 \\
\hline & & Becomes normal (10 $\mathrm{mmHg}$ to $21 \mathrm{mmHg}$ ) & 5 \\
\hline \multirow{6}{*}{33} & \multirow{6}{*}{ Tonometry IOP low } & Not afflicted in vision & NAA \\
\hline & & $0 \mathrm{~mm}$ & 1 \\
\hline & & 1 to $3 \mathrm{~mm}$ & 2 \\
\hline & & 4 to $6 \mathrm{~mm}$ & 3 \\
\hline & & 6 to $9 \mathrm{~mm}$ & 4 \\
\hline & & Becomes normal (10 $\mathrm{mmHg}$ to $21 \mathrm{mmHg}$ ) & 5 \\
\hline
\end{tabular}

\section{Scientific Research Publishing}

Submit or recommend next manuscript to SCIRP and we will provide best service for you:

Accepting pre-submission inquiries through Email, Facebook, LinkedIn, Twitter, etc. A wide selection of journals (inclusive of 9 subjects, more than 200 journals)

Providing 24-hour high-quality service

User-friendly online submission system

Fair and swift peer-review system

Efficient typesetting and proofreading procedure

Display of the result of downloads and visits, as well as the number of cited articles Maximum dissemination of your research work

Submit your manuscript at: http://papersubmission.scirp.org/

Or contact ojoph@scirp.org 